\title{
Study on Developmental Psychology of Undergraduate Network Addiction Phenomenon
}

\author{
Sujing Li \\ Shandong Foreign Language Vocational College, Rizhao, 276826, China
}

Keywords: Undergraduate; Network addiction; Developmental psychology

\begin{abstract}
With gradual development of information technology, network has become an indispensible part in daily life. Meanwhile, teenagers' network addiction phenomenon receives more and more attention. Simply speaking, network addiction refers to a mental phenomenon of indulging in network. This paper mainly analyzes undergraduate network addiction phenomenon and especially the psychological factors. This paper hopes to overall master undergraduate network addiction issue from psychology and actively explore the methods to overcome network addiction.
\end{abstract}

\section{Introduction}

As everyone knows, undergraduates are the major group to contact network. On the one hand, because of current network popularization, undergraduates own the basic conditions to surf the internet; on the other hand, undergraduates actually need network. As networks popularization, undergraduate network addiction issue gradually triggers social attention. This paper analyzes undergraduate network addiction from the perspective of developmental psychology, and expects to better help undergraduates to get rid of network addiction and more rationally utilize network to serve their study and life.

\section{Developmental psychology manifestation of undergraduate network addiction phenomenon}

It is found through analysis that factors of undergraduate network addiction mainly include physiological factors and psychological factors. This paper explains it from the perspective of developmental psychology.

From the perspective of developmental psychology, undergraduates are in the late puberty and do not really grow up. So, although their physiology approaches adults, their psychology is still immature. Psychological characteristics of undergraduates are as follows:

Seeing from developmental psychology, undergraduates present very strong physical development mental phenomenon. As their physiology gradually becomes mature, their outlook on life, values and social outlook gradually form. They own significant adult physical development mental phenomenon.

Undergraduates' living range is gradually expanding. Here, living range, on the one hand, refers to their social contract range in real life; on the other hand, it refers to their psychological social contact range. As their social contact range expands, their psychology is changing subtly. Form the perspective of developmental psychology, self-abasement and sensitivity may appear.

Their sex consciousness gradually becomes mature. As undergraduates' physiology gradually becomes mature, their sex consciousness basically approaches adults. From the perspective of developmental psychology, their mature sex consciousness makes them generate strong wish to get along with and contact with those of opposite sex. This is also a prominent expression of their physical development psychology.

\section{Developmental psychology explanation of undergraduate network addiction phenomenon}

From the perspective of developmental psychology, the causes for undergraduate network addiction mainly include the following: 


\section{Deficiency in psychological satisfaction}

It is discovered through analysis that the first factor for undergraduate network addiction is the deficiency in psychological satisfaction. As the graduation from senior high schools, undergraduates' academic burden is relieved. On the one hand, this makes undergraduates have time to participate in other social activities; on the other hand, this causes that psychological deficit appears to some undergraduates. Due to the disappearance of intense academic burden and the decrease in pressure of entering a higher school, some undergraduates gradually show psychological deficit. The main manifestations are as follows: they are not interested in anything; they are satisfied with a smattering of knowledge. This is because most undergraduates are used to learning under the supervision and pressure of parents and teachers, so they lack independent study and self-discipline ability, thus resulting in deficiency in psychological satisfaction. Undergraduate deficiency in psychological satisfaction in real society will easily make them seek satisfaction from the virtual society - network. Since undergraduates may reach to network conveniently, they may gain psychological satisfaction from network. Although such psychological satisfaction is transitory and virtual, bemuse it caters to undergraduate deficiency in psychological satisfaction, it is welcomed by undergraduates. Meanwhile, many undergraduates have network addiction.

\section{Role transition and pressure diversity}

As undergraduate role changes, their life pressure gradually transforms to pressure of various aspects from academic pressure. Through exchange with undergraduates, we find most undergraduates keep living and learning habits when they were in the senior high school. As times passes, sufficient self-discipline ability makes most undergraduates unable to fast adapt diversified college life. Plus love, emotional experience and life pressure, they may easily tend to seek comfort from internet world. Some undergraduates have insufficient strong self-care ability and self-discipline ability, because they are used to the learning under supervision and help of their parents and teachers. Besides, due to influence of other undergraduates, they may easily contact network. Transitory, fast and strong stimulus brought by network makes undergraduates indulge in it. As undergraduates gradually indulge in network, their learning interest gradually reduces. Unsatisfactory academic results make some undergraduates have fuzzy learning objectives. The vision and lofty aspirations when the just entered the campus are replaced by cruel reality. This also causes they seek comfort from network world.

\section{Gradual formation of self-awareness, outlook on life and world outlook}

As undergraduate physiology becomes gradually mature, their psychology also becomes gradually mature. This is reflected in the maturity of their self-awareness. So-called self-awareness means undergraduates start to realize their position in society and gradually transform to complex self-knowledge from single social cognition. On the one hand, such self-awareness is reflected in their environmental cognition; on the other hand, this is reflected in their position cognition in the environment. As their self-knowledge becomes gradually mature, self-abasement and depravation appear to some undergraduates. They consider they have a large gap with their peers. Especially for some poor students, such psychological experience is especially obvious. Self-awareness development and imperfect self-evaluation cause that some undergraduates reduce their expectation for college life. In their opinions, college life is the life of enjoyment and playing. After fierce competition in college entrance examination and high-intensity academic pressure, some undergraduates fail to fully cognize sudden college life. They fail to realize they should better improve themselves in the college, but are anxious to relieve pressure in the senior high school. This also makes undergraduates more easily indulge in network world.

As undergraduates gradually form world outlook and outlook on life, their views on society gradually become rich. Different from simple cognition of society in their senior high school, undergraduates' cognition of society is more three-dimensional and rich. Some undergraduates have 
felt social pressure in college environment. On the one hand, such pressure comes from learning and living pressure brought by classmates and friends; on the other hand, the pressure comes from employment and examination pressure brought by parents. In the face of pressure, some undergraduates present concession and cowardice tendency. They dare not face up to pressure and challenge pressure, but are anxious to avoid pressure. At this time, virtual network society can bring them transient and fast satisfaction. Hence, network may be easily accepted and favored by undergraduates. This also results in undergraduate network addiction.

\section{Effect of group psychology}

Psychologically, group psychology is human general psychology. Its basis lies in human nature of drawing on advantages and avoiding disadvantages. On the one hand, undergraduate network addiction is due to poor self-discipline ability and lack of effective countersues to external pressure; on the other hand, it is because of the effect of group psychology. Some undergraduates consider all do this, so this indicates it is popular and imposes no damage. Some see roommates play games and watch movies on network, and they cannot resist the lure and pressure from roommates. Some undergraduates even consider they have no common topic with classmates if they do not play online games, watch movies on network and TY plays. Thus, some undergraduates easily yield to network addiction. Besides, psychological hint makes some undergraduates college life should be like this. So, they ignore self-knowledge and thought on their own value. The lure of network makes undergraduates doubt their life and learning modes. They hold that their living and learning modes are not fashionable enough and not consistent with their living and learning ways, so group psychology may be easily generated.

\section{Undergraduate view limitation}

Since some undergraduates do not really form world outlook and outlook on life, they fail to comprehensively cognize their living environment. Du to their view limitation, some undergraduates believe society and college have no big differences. Thus, they have no complete and all-round planning for their school work and life. This also makes them fuzz up their positioning. Seeing from developmental psychology, human all-round development derives from comprehensive development in different life stages, while undergraduates are in the golden stage of their life. Some undergraduates fail to fully cognize life and society, so their pleasure - seeking thought prevails. They even indulge in enjoyment. Virtuality and low cost of network world make undergraduates easily captured by it. Some undergraduates also indulge in network and believe this is the joy of life. Thus, they ignore self-development. In general, this is because their one-sided cognition of society and life causes they are captured by transitory and virtual stimulus brought by network.

\section{Lack of intimacy}

It is found through researches that some undergraduates indulge in network world, because they lack intimacy. After undergraduates enter universities, their intimacy gradually declines, because they keep away from their parents and relatives. On the one hand, this is because exchanges with friends and relatives reduce; on the other hand, this is due to their character factor. Some are introverted and not good at communication, so adaptive capacity to new environment is low. Moreover, their communications with classmates and teachers are few, so they form solitary and farouche character. Such character may easily make undergraduates seek comfort from network. Because undergraduates can contact network conveniently and network communication is fast and convenient, some undergraduates gradually replace real society with network society. In addition to this, solitary and introverted character makes some dare not exchange and contact with those of opposite sex. This also causes undergraduates fail to fully cognize emotions, while they can exchange with those of opposite sex easily in network world. It is found through researches that some undergraduates can exchange with those of opposite sex at will skillfully in network world, while in real society, they are not self-confident enough. Some undergraduates indulge in making friends via 
network and even are willing to meet virtual friends. However, they are unwilling to communicate in real life. Thus, some undergraduates may be easily attracted by network.

\section{Solutions to undergraduate network addiction}

We realize through the above analysis that undergraduates should first perfect their outlook on life and world outlook in order to get rid of network addiction. Moreover, they should enhance self-discipline ability and realize real society is more worthy of noticing except network. Meanwhile, undergraduates must formulate perfect occupational planning and life planning and blend their occupational planning and life planning in daily efforts. They should overcome group psychology, stick to their life goal, and resist lure and pressure. As well, they should take active part in social exchanges, attach importance to social contact activities in campus and cultivate more hobbies so as to make more friends in real life.

Undergraduates should establish correct outlook on life and values, implement self-development in daily unremitting endeavors, abandon hedonism and nihilism and persist in fine tradition of hard work and plain life. Based on analysis of college education contents and modes as well as undergraduates' physiological age and psychological development, college ideological and political educators must start from numerous problems faced by undergraduates and solve contradictions. Based on current situations, undergraduate network addiction phenomenon should not merely blame for college education. Education and ideas they receive in their family stage, primary school stage and middle school stage as well as their view of life values become sufficient and necessary causes for their network addiction.

Undergraduates should really improve self-discipline ability, have a clear understanding of their environment, blend self-development in realistic society, and value social exchange and interpersonal relationship. At the same time, they should seek more help from teachers and classmates. Once they find network addition phenomenon, they should seek psychological guidance in time. Universities, parents and other educators should really know undergraduates' mental dynamics, adopt corresponding measures and help them get rid of network addiction.

\section{Conclusions}

In conclusion, this paper conducts developmental psychology analysis of undergraduate network addiction. Firstly, this paper analyzes the causes for undergraduate network addiction. Secondly, specific solutions are proposed. Through developmental psychology analysis, we realize the major factor of undergraduate network addiction is that their outlook on life and values do not really form and they have poor self-requirement and self-discipline ability. Hence, undergraduates must correctly understand network and correctly cognize individual role, clearly know their position and development goal so as to better confirm life goal and rationally plan life.

\section{References}

[1] Guo Nianfeng, Basic knowledge of psychological counselor. Nationalities Publishing House, 2005.7

[2] Yang Kexu, Wang Lili, Exploration of intervention mode of undergraduate network dependence. Ideological \& Theoretical Education, 2008,(13)

[3] Chen Donghong, Psychology remedy of undergraduate network addiction based on the perspective of counselors. Journal of Yichun University, 2008,(04). 
[4] Cai Fei, Review of generalized personality development theory. Psychological Science, 2008,31(04)

[5] Li Huanhuan, Wang Li, Wang Jiaqi, Difference of undergraduates with internet addiction in mental health status and the relationship with personality. Chinese Journal of Clinical Psychology, 2008,16(04) 